\title{
Cannabis use is associated with a lower risk of diabetes in chronic hepatitis C-infected patients (ANRS CO22 Hepather cohort)
}

\section{Running title}

Cannabis use and diabetes in HCV patients

Tangui Barré ${ }^{1,2}$, Marie Libérée Nishimwe ${ }^{1,2}$, Camelia Protopopescu ${ }^{1,2}$, Fabienne Marcellin $^{1,2}$, Fabrice Carrat ${ }^{3}$, Céline Dorival ${ }^{4}$, Elisabeth Delarocque-Astagneau ${ }^{5}$, Dominique Larrey $^{6}$, Marc Bourlière ${ }^{7}$, Ventzislava Petrov-Sanchez ${ }^{8}$, Mélanie Simony $^{8}$, Stanislas Pol*9, Hélène Fontaine ${ }^{\star 10,11}$ and Patrizia Carrieri ${ }^{1,2}$ on behalf of the ANRS/AFEF Hepather study group

${ }^{1}$ Aix Marseille Univ, INSERM, IRD, SESSTIM, Sciences Économiques \& Sociales de la Santé \& Traitement de l'Information Médicale, Marseille, France;

2 ORS PACA, Observatoire régional de la santé Provence-Alpes-Côte d'Azur, Marseille, France;

${ }^{3}$ Sorbonne Université, Institut National de la Santé et de la Recherche Médicale (INSERM), Institut Pierre Louis d'Epidémiologie et de Santé Publique, Paris, France; Assistance Publique-Hôpitaux de Paris (AP-HP), Hôpital Saint-Antoine, Unité de Santé Publique, Paris, France;

${ }^{4}$ Sorbonne Université, Institut National de la Santé et de la Recherche Médicale (INSERM), Institut Pierre Louis d'Epidémiologie et de Santé Publique, Paris, France;

${ }^{5}$ UMR1181 Biostatistique, Biomathématique, Pharmaco-épidémiologie et Maladies Infectieuses (B2PHI), Institut Pasteur, Inserm, Université de Versailles-Saint-Quentin-enYvelines (UVSQ), Paris, France; 
${ }^{6}$ Service des maladies de l'appareil digestif, Hôpital Saint Eloi, IBR- Inserm Montpellier, France ;

${ }^{7}$ Department of Hepatology and Gastroenterology, Hôpital Saint Joseph, Marseille, France;

${ }^{8}$ ANRS (France Recherche Nord \& Sud Sida-HIV Hépatites), Unit for Basic and Clinical Research on Viral Hepatitis, Paris, France ;

${ }^{9}$ Université de Paris ; AP-HP, Hôpital Cochin, Département d'Hépatologie; INSERM U1223, Institut Pasteur, Paris, France;

${ }^{10}$ AP-HP, Hôpital Cochin, Département d'Hépatologie, Paris, France;

11 INSERM U1223, Institut Pasteur; Université Paris Descartes, Paris, France.

* SP and HF made an equal contribution to the work.

\section{Acknowledgments}

The cohort received financial support from the INSERM-ANRS (France Recherche Nord \& Sud Sida-HIV Hépatites), the French ANR (Agence Nationale de la Recherche), the French DGS (Direction Générale de la Santé), Merck Sharp and Dohme, Janssen-Cilag, Gilead, Abbvie, Bristol-Myers Squibb, and Roche. Those funding sources had no role in the writing of the manuscript or the decision to submit it for publication.

We thank the study participants and the participating clinicians at each site. We also thank the INSERM-ANRS for sponsoring, funding and conducting the ANRS CO22 Hepather cohort in collaboration with the French Association for the Study of the liver (Association Française pour l'Etude du Foie: AFEF). Finally, our thanks to Jude Sweeney for the English revision and editing of our manuscript. 


\section{ANRS-AFEF Hepather study group}

Delphine Bonnet, Virginie Sicart (CHU Purpan, Toulouse, France), François Bailly,Marjolaine Beaudoin, Dominique Giboz, Kerstin Hartig-Lavie, Marianne Maynard(Hospices Civils de Lyon, Lyon, France), Morane Cavellec, Marjorie Cheraud-Carpentier, François Raffi, Florian Vivrel (Hôpital Hôtel-Dieu, Nantes, France), Jaouad Benhida, Jérôme Boursier, Paul Calès, Françoise Lunel, Frédéric Oberti (CHU Angers, Angers, France), Nathalie Boyer, Audrey Gilibert, Nathalie Giuily (Hôpital Beaujon, Clichy, France), Giovanna Scoazec (Hôpital Beaujon, Clichy, France and Hôpital Henri Mondor, Créteil, France), Sandrine Fernandes, Sylvie Keser, Philippe Sultanik, Anaïs Vallet-Pichard (Hôpital Cochin, Paris, France), Juliette Foucher, Jean-Baptiste Hiriart, Aurore Mathias, Julien Vergniol (Hôpital Haut-

Lévêque, Pessac, Bordeaux, France), Chrystelle Ansaldi, Laëtitia Chouquet, Emilie

De Luca, Valérie Oules (Hôpital Saint Joseph, Marseille, France), Rodolphe Anty, Eve Gelsi, Régine Truchi (CHU de Nice, Nice, France), Elena Luckina, Nadia Messaoudi, Joseph Moussali, (Groupe Hospitalier Pitié-Salpétrière, Paris, France), Barbara De Dieuleveult, Damien Labarriere, Pascal Poter, Si Nafa Si Ahmed (CHR La Source, Orléans, France), Nathalie Ganne-Carrié, Véronique Grando-Lemaire, Pierre Nahon, Alan Peltier, Judith Ung (Hôpital Jean Verdier, Bondy, France), Mariette Gougeon, Anne Guillygomarch, Caroline Jezequel (CHU Rennes, Rennes, France), Romain Moirand, Thomas F. Baumert, Michel Dofföel, Catherine Mutter, Pauline Simo-Noumbissie (Hôpitaux Universitaires de Strasbourg, Strasbourg, France), Hélène Barraud, Mouni Bensenane, Abdelbasset Nani, Sarah HassaniNani (CHU de Nancy, Vandoeuvre-lès-Nancy, France), Marie-Albertine Bernard (CHU de Nancy, Vandoeuvre-lès-Nancy, France and Centre Hospitalier Régional, Metz, France), Michael Bismuth, Ludovic Caillo, Stéphanie Faure, Georges-Philippe Pageaux, Marie Pierre Ripault (Hôpital Saint Eloi, Montpellier, France), Karl Barange, Christophe Bureau, Jean Marie Peron, Marie Angèle Robic, Léa Tarallo (CHU Purpan, Toulouse, France), Marine Faure, Bruno Froissart, Marie-Noelle Hilleret, Vincent Leroy (CHU de Grenoble, Grenoble, 
France), Odile Goria, Victorien Grard, Hélène Montialoux (CHU Charles Nicolle, Rouen, France), Muriel François, Christian Ouedraogo, Christelle Pauleau, Anne Varault (Hôpital Henri Mondor, Créteil, France), Tony Andreani, Bénédicte Angoulevant, Azeline Chevance, Lawrence Serfaty (Hôpital Saint-Antoine, Paris, France), Teresa Antonini, Audrey Coilly, Jean-Charles Duclos Vallée, Mariagrazia Tateo (Hôpital Paul Brousse, Villejuif, France), Armand Abergel, Corinne Bonny, Chanteranne Brigitte, Géraldine Lamblin, Léon Muti (Hôpital Estaing, Clermont-Ferrand, France), Abdenour Babouri, Virginie Filipe (Centre Hospitalier Régional, Metz, France), Camille Barrault, Laurent Costes, Hervé Hagège, Soraya Merbah (Centre Hospitalier Intercommunal, Créteil, France), Paul Carrier, Maryline Debette-Gratien, Jérémie Jacques (CHU Limoges, Limoges, France), Florent Artu, Valérie Canva, Sébastien Dharancy, Alexandre Louvet (CHRU Claude Huriez, Lille, France), Marc Bardou, Donya Da Costa Souhiel, Patrick Hillon, Marianne Latournerie (Dijon University Hospital, Dijon, France), Yannick Bacq, Didier Barbereau, Charlotte Nicolas (CHU Trousseau, 37044 Tours, France), Nisserine Ben Amara, Danièle Botta-Fridlund, Isabelle Portal (CHU Timone, Marseille, France), Moana Gelu-Simeon, Marie-Josée Lafrance (CHU de Pointe-à-Pitre, Pointe-à-Pitre, Guadeloupe).

\section{Financial support statement (authors):}

FC reports grants from INSERM-ANRS, during the conduct of the study; and personal fees from Imaxio, outside the submitted work. MB reports grants and personal fees from AbbVie and Gilead, outside the submitted work; and personal fees from MSD, Janssen, Boehringher Ingelheim, Intercept, and Bristol-Myers Squibb, outside the submitted work. SP has received consulting and lecturing fees from Bristol-Myers Squibb, Janssen, Gilead, Roche, MSD, MYRPharma, Shionogi, Biotest and Abbvie, as well as grants from Bristol-Myers Squibb, Gilead, Roche and MSD. HF reports personal fees and invitations for medical meetings from Gilead, AbbVie, Bristol-Myers Squibb, MSD, and Janssen, outside the submitted work. Other authors declare no financial support.

\section{Trial statement}


Data were derived from a trial registered with ClinicalTrials.gov, number NCT01953458. Written informed consent was obtained from each cohort participant before enrolment. The protocol was designed in accordance with the Declaration of Helsinki and French law for biomedical research, and was approved by the 'Comite de Protection des Personnes (CPP) Ile de France 3' Ethics Committee (Paris, France) and the French Regulatory Authority (ANSM). 


\section{Abstract}

Background \& Aims: Chronic hepatitis C virus (HCV) infection is a risk factor of insulin resistance, and $\mathrm{HCV}$-infected patients are at a high risk of developing diabetes. In the general population, research has shown the potential benefit of cannabis use for the prevention of diabetes and related metabolic disorders. We aimed to test whether cannabis use is associated with a lower risk of diabetes in chronic HCV-infected patients.

Methods: Chronic HCV-infected patients $(n=10,445)$ were selected from the French national, multicenter, observational ANRS CO22 Hepather cohort. Crosssectional data collected at cohort enrolment were used to assess the association between patients' clinical and behavioral characteristics and the risk of diabetes. Logistic regression model was performed with cannabis use as the main independent variable and a significance level set at $5 \%$. A similar model stratified by the presence of advanced liver fibrosis (FIB-4>3.25) was also run.

Results: After multivariable adjustment, current (AOR [95\%Cl]: 0.49 [0.38$0.63])$ and former $(0.81$ [0.67-0.98], $p<.001)$ cannabis use were both associated with a reduced odds of diabetes. Conversely, male gender, tobacco use, elevated BMI, poverty, being a migrant and advanced fibrosis were associated with increased odds of diabetes. The association between cannabis use and diabetes was maintained in the stratified analysis.

Conclusions: In this large cross-sectional study of chronic HCV-infected patients, cannabis use was associated with a lower risk of diabetes independently of clinical and socio-behavioral factors. Further studies are needed to elucidate a potential 
causal link and shed light on cannabis compounds and mechanisms involved in this relationship.

\section{Keywords:}

Hepatitis C, Chronic; Cannabis; Diabetes Mellitus; Marijuana Smoking; France.

\section{Introduction}

With a global prevalence of over 500 million cases in 2018, type 2 diabetes is a growing health and economic burden ${ }^{1,2}$, associated with increased all-cause mortality $^{3}$. In 2015, the number of hepatitis C virus (HCV) viremic infections was estimated at more than 71 million worldwide. $\mathrm{HCV}$ is a leading cause of death and disability, especially through cirrhosis ${ }^{4,5}$. HCV and diabetes are reciprocally intertwined: HCV infection triggers diabetes (mostly type 2) and diabetes worsens HCV outcomes, for instance by increasing the risk for cirrhosis ${ }^{6}$. Furthermore, the treatment of diabetes in cirrhotic patients is complex ${ }^{7}$. Diabetes is the second most common extrahepatic manifestation of HCV infection ${ }^{8}$. HCV infection is assumed to lead to hepatic insulin resistance through direct impairment of the hepatocyte insulin signaling pathway and to peripheral insulin resistance through hepatic production of mediators $^{9}$. Insulin resistance constitutes the pathological background for type 2 diabetes development, and may also trigger hepatic steatosis, the latter being also promoted directly by $\mathrm{HCV}$ infection ${ }^{10}$. A difference is sometimes made between type 2 diabetes and a state of impaired glucose regulation caused by loss of liver function as a consequence of cirrhosis (referred to as 'hepatogenous diabetes') ${ }^{7}$. 
In high-income countries, the HCV burden is mainly felt in marginalized populations ${ }^{11}$ such as people who inject drugs and homeless people. In Europe, injecting drug use is the main route of $\mathrm{HCV}$ transmission ${ }^{12}$. Moreover, people who inject drugs face many barriers to access to care ${ }^{13,14}$. A higher HCV prevalence is associated with lower income, lower education level and less employment ${ }^{15}$. In parallel, a low socioeconomic status is associated with poorer health in general ${ }^{16}$, and with higher type 2 diabetes incidence in particular ${ }^{17}$. HCV-infected patients' susceptibility to diabetes may therefore be exacerbated by socioeconomic factors.

In the general population, studies examining the association between cannabis use and the risk of diabetes have yielded inconclusive results, while results showing the protective effect of cannabis in terms of other metabolic disorders seem more conclusive ${ }^{18}$. In a cross-sectional analysis of HIV-HCV co-infected patients, cannabis use, irrespective of frequency, was associated with lower odds of insulin resistance after adjustment for known confounders ${ }^{19}$. In chronic $\mathrm{HCV}$-infected patients, cannabis use was also associated with better liver disease outcomes ${ }^{20}$. However, there is still a lack of data regarding the association between cannabis use and the risk of type 2 diabetes in HCV mono-infected patients. Using data from the French ANRS CO22 Hepather cohort, we aimed to test whether cannabis use is inversely associated with type 2 diabetes in $\mathrm{HCV}$-infected patients.

\section{Material and methods}

\section{Participants}

ANRS CO22 Hepather is a French national, multicenter, prospective, observational cohort of adult hepatitis B (HBV)- and HCV-infected patients (registered with ClinicalTrials.gov, number NCT01953458). The cohort design has 
been extensively described elsewhere ${ }^{21}$. Set up in 2012, enrolment in the study took place in 32 centers throughout France. Patients were recruited during a medical follow-up visit in their center (eligible patients were proposed to participate in the cohort). Demographic, clinical and biological data were collected at the inclusion visit. Patients were followed-up on a yearly basis, and supplemental data were also collected during visits related to particular events (e.g., initiation of HBV or HCV therapy). Written informed consent was obtained from each cohort participant before enrolment. The protocol was designed in accordance with the Declaration of Helsinki and French law for biomedical research, and was approved by the 'Comité de Protection des Personnes (CPP) lle de France 3' Ethics Committee (Paris, France) and the French Regulatory Authority (ANSM).

The present study population comprised patients with chronic HCV (defined as positive HCV-RNA and anti-HCV antibodies) at cohort recruitment. The main exclusion criteria in Hepather were HIV co-infection, being on HCV-treatment or having stopped HCV treatment for less than 3 months at recruitment. We also excluded patients with no data on diabetes diagnosis $(n=145)$ and patients with no cannabis use data $(n=533)$, leaving us with a study sample of 10,445 patients (Figure 1).

\section{Data collection}

At the enrolment visit, patients completed a face-to-face interview with their physician based on a structured questionnaire. Anthropological measurements and urine and blood samples were also taken.

Data collected in the questionnaire included: lifetime (yes/no) and current (yes/no) cannabis use, current tobacco use (yes/no), current alcohol consumption (number of 
standard drinks per day), current coffee consumption (number of cups per day), household income (average monthly income) and own and parents' country of birth. Body height and weight were measured. Data derived from blood samples included platelet count (platelets $/ \mathrm{mm}^{3}$ ), aspartate aminotransferase (AST, IU/ L) and alanine aminotransferase (ALT, IU/L).

\section{Outcome}

The variable 'presence of diabetes' was used as the outcome. Diabetes diagnosis ('Yes/No') was established based on a confirmed fasting blood sugar level of at least $126 \mathrm{mg} / \mathrm{dL}(7.0 \mathrm{mmol} / \mathrm{L})$ and/or uptake of antidiabetic drugs.

\section{Explanatory variables}

People who answered 'yes' to the question concerning current use of cannabis were classified into the 'current use' category. Among people who answered 'no', those who reported lifetime cannabis use were classified into the "lifetime use" category. Finally, people who answered 'no' to both questions (current/lifetime use) were classified into the 'no lifetime use' category. We therefore ended up with a three-level cannabis variable. According to previous studies in HIV-HCV co-infected patients, elevated coffee consumption was defined as 3 or more cups of coffee per day ${ }^{22}$. A second threshold at 4 cups of coffee was also tested. A meta-analysis highlighted a decrease in relative risk of diabetes by 1 cup per day increase ${ }^{23}$. Poverty was defined as a standard of living lower than the 2015 French poverty threshold $(1,015 €$ per month). Standard of living was calculated as disposable income divided by the number of consumption units in the household. Being a migrant was defined as being born outside France and having at least one parent also born outside France. Liver fibrosis was assessed through FIB-4 calculation, based on age, platelet count, AST and ALT using the following formula: (age [years] * AST [IU/L])/(platelet count [109/L] 
* $\left.(\text { ALT [IU/L] })^{1 / 2}\right)$. A cut-off $>3.25$ was used to define advanced fibrosis ${ }^{24}$. The following variables were also tested as explanatory variables: gender, age, current tobacco use (yes/no), current alcohol consumption (abstinent, moderate, elevated), and body mass index (BMI) with the following WHO classes ${ }^{25}$ : $<18.5$, underweight; $\geq 18.5$ and $<25$, normal weight; $\geq 25$ and $<30$, overweight; $\geq 30$, obese. Elevated alcohol consumption was defined as $>2$ standard drinks per day for women and $>3$ standard drinks per day for men, according to French National Authority for Health ${ }^{26}$.

\section{Statistical analyses}

The characteristics of diabetic patients were compared with those of non-diabetic patients using a Chi-square test (categorical variables) or Student's t-test (continuous variables). Similarly, the characteristics of the study population were compared between cannabis use status (using Fisher's test for continuous variables). Logistic regression models were used to test the association between cannabis use and diabetes at cohort entry, after adjustment for other potential predictors. Only variables with a liberal $p$-value $<0.20$ in the univariable analyses were considered eligible for the multivariable mode ${ }^{27}$. The final multivariable model was built using a backward stepwise procedure and the likelihood ratio test $(p<0.05)$ was used to define the variables to be maintained in the model. An interaction between cannabis use and $\mathrm{BMI}$ was tested for in the final model because cannabis use is known to be associated with a lower BMI ${ }^{18}$. Because cirrhosis is diabetogenic ${ }^{7}$, similar logistic regressions stratified by fibrosis status were also performed to test whether the relationship between cannabis use and diabetes may differ between patients with advanced fibrosis and other patients. Results from logistic regression models were presented as odds ratios and adjusted odds ratios (for the multivariable model), with 
the corresponding $95 \%$ confidence intervals. The level of significance was set at $\alpha=0.05$ in all tests. SAS version 9.4 software was used for all analyses.

\section{Results}

\section{Study population characteristics}

The characteristics of the study population are presented in Tables 1 and 2 .

The study population was mainly male (56.6\%). Median age was 56 years and $13.7 \%$ of the patients had diabetes. A majority of the study population had never used cannabis $(67.3 \%), 18.7 \%$ were former users and $14.0 \%$ were current users.

\section{Multivariable analyses}

Despite being significantly associated with diabetes in univariable analysis, elevated coffee consumption ( $\geq 3$ cups/day) was not significantly associated with the presence of diabetes $(p=0.54)$ in the multivariable analysis. Increasing the threshold to $\geq 4$ cups/day did not change this result $(p=0.30)$. Accordingly, this variable was removed from the final model. Results for the final model are given in Table 3. When artificially maintained in the model, it did not change other relationships between the explicative and dependent variables.

Current and former cannabis use were both associated with a lower odds of diabetes (compared with 'no lifetime use') (adjusted odds-ratio (OR), 95\% confidence interval (Cl): 0.49 [0.38-0.63] and 0.81 [0.67-0.98], respectively). The lower odds of diabetes in current users than in former users was statistically significant $(0.60[0.46-$ $0.80], p=0.0003$ ). Older age and being a man were positively associated with higher odds of diabetes. BMI classes displayed a dose-dependent relationship with the odds 
of diabetes. Moderate alcohol consumption was associated with a $23 \%$ lower odds of diabetes (compared with abstinence), while current tobacco use was associated with a $17 \%$ increased odds (Table 3 ). Both poverty and being a migrant were positively associated with the odds of diabetes, while individuals with advanced liver fibrosis had a $71 \%$ increased odds of diabetes. The interaction term between cannabis use and BMI was not statistically significant $(p=0.23)$.

When comparing individuals included in the multivariable analysis with those excluded $(n=1,230)$ because of missing values, the former were older (56.8 vs. 54.8 years, $p<0.001)$, more likely to be male ( 55.7 vs. $52.3 \%, p=0.023)$, less likely to be current smokers (37.2 vs. $40.5 \%, p=0.028$ ), and more likely to have elevated coffee consumption ( 69.3 vs. $64.6 \%, p<0.001)$. When stratifying by fibrosis status, current cannabis use was associated with a lower odds of diabetes (compared with 'no lifetime use') in patients with and without advanced fibrosis (Supporting tables $1 \& 2$ ).

\section{Discussion}

Using cross-sectional data from more than 9,000 HCV-infected patients, we found that former and current cannabis use were associated with, respectively, a $19 \%$ and $51 \%$ lower risk of diabetes when compared with no lifetime cannabis use. To our knowledge, this is the first time that such an association has been highlighted for HCV-infected patients. Under the assumption that the pattern of cannabis use differs only in terms of duration between former (shorter exposure) and current users (longer exposure), our results suggest that the potential protective effect of cannabis displays a dose-dependent relationship.

Our results are consistent with a meta-analysis in the U.S general population based on the National Health and Nutrition Examination Surveys (NHANES) and the 
National Surveys on Drug Use and Health ${ }^{28}$. In that meta-analysis, recently active cannabis smoking and diabetes were inversely associated (compared with no lifetime cannabis use), with a summary odds-ratio of 0.7 [0.6-0.8]. This confirmed previous results from NHANES data which compared lifetime use with no lifetime use ${ }^{29}$. However, the only longitudinal analyses available revealed no association between cannabis use and incidence of diabetes in the general population ${ }^{30,31}$, while cannabis use in young adulthood was associated with prediabetes incidence in middle age ${ }^{31}$. Beyond specificities due to HCV infection, differences in lifestyle or cannabis material and practices may impair comparability between those studies coming from Sweden and the U.S. Moreover, in the Swedish study the prevalence of current cannabis use was very low ${ }^{30}$.

Insulin resistance is closely related to other metabolic dysregulations and to metabolic syndrome. The effects of cannabis use on BMI, obesity and other metabolic dysregulations are still controversial but tend to indicate that there is a beneficial effect ${ }^{18,32}$. Several cannabis compounds exerting potential beneficial effects on these risk factors for diabetes have been identified. The endocannabinoid system controls energy intake via both central and peripheral mechanisms, as well as energy storage and expenditure, with direct implications for the development of type 2 diabetes $^{33}$. Exogenous cannabinoids from cannabis are likely to interact with the endocannabinoid system and its control of energy balance. For instance, cannabidiol, a major non-psychotropic constituent of cannabis, decreases both body weight and

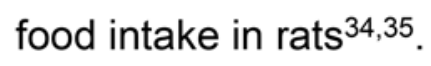

Given that diabetes pathogenesis in $\mathrm{HCV}$-infected patients involves specific mechanisms, the effects of cannabis use we found may be partly mediated by mechanisms different from those observed in the general population. For instance, 
$\mathrm{HCV}$ infection causes systemic inflammation ${ }^{36}$, this latter being a likely contributor to type 2 diabetes occurrence ${ }^{37,38}$. As cannabidiol found in cannabis possesses antiinflammatory properties ${ }^{39}$, this indirect action may lead to a stronger effect of cannabis on diabetes in HCV-infected patients. Moreover, HCV-infected patients are at greater risk of liver disease, and cirrhosis is diabetogenic ${ }^{7}$. Accordingly, we found that advanced liver fibrosis is a risk factor for diabetes. Based on a large database of USA hospital discharge records, Adejumo et al. found that cannabis use was associated with a lower prevalence of liver cirrhosis among chronic HCV-infected patients ${ }^{20}$. Among users, while the difference was not statistically different, dependent users had an even lower prevalence of liver cirrhosis than non-dependent users. This is in line with our results showing a lower risk of diabetes among current cannabis users than in former users. While a recent systematic review and metaanalysis concluded that there is no association between cannabis use and progression of liver fibrosis in HCV and HIV-HCV co-infected patients ${ }^{40}$, the mediating effect of fibrosis and/or cirrhosis between cannabis and diabetes deserves further investigation. However, as the analyses in the present study were adjusted for advanced liver fibrosis, we hypothesize that other mechanisms are involved. Patients achieving sustained virological response (SVR) after interferon-based therapy exhibited improvements in HOMA-IR and HOMA- $\beta$, but no impact was found on insulin resistance ${ }^{41}$. In the era of direct-acting antivirals for HCV, SVR rates of almost $100 \%$ are being reached, inducing clear benefits on the alteration of homeostasis of glucose metabolism associated with HCV infection, including improvement of insulin resistance and reduced onset of de novo insulin resistance and type 2 diabetes in patients without advanced cirrhosis or long-term diabetic history ${ }^{42}$. For HCV patients with type 2 diabetes, whether the beneficial short-terms outcomes of DAA-induced 
$\mathrm{HCV}$ clearance are maintained and of clinical significance in the long term remains unclear $^{43}$.

The endocannabinoid system is present in the liver and is involved in the control of various hepatic functions ${ }^{44}$. Noticeably, hepatic cannabinoid receptor CB1 activation contributes to obesity-related insulin resistance. Endocannabinoids may also be directly involved in diabetes development, given that they may favor beta cell failure through peripheral $\mathrm{CB} 1$ receptors ${ }^{45}$. One can hypothesize that exogenous cannabinoids from cannabis interact with peripheral and/or hepatic endocannabinoid systems. For instance, chronic administration in patients with type 2 diabetes of delta-9-tetrahydrocannabivarin (THCV), which is found in cannabis, leads to a reduction of fasting plasma glucose and improved pancreatic $\beta$-cell function without affecting body weight or appetite ${ }^{46}$. These effects could explain the seemingly protective effect of cannabis use on diabetes development, even if other cannabis compounds may be involved, directly or through interaction with one another.

The gender difference in the risk of diabetes observed in our study is wellknown and is mediated through endocrine and behavioral factors ${ }^{47}$. The increased risk of diabetes associated with current tobacco use has already been shown in the general population ${ }^{48}$ and seems to be mediated through an impact on body weight, body composition, peripheral insulin sensitivity and pancreatic beta cell function ${ }^{49}$. Moderate alcohol consumption has previously been identified as protecting against type 2 diabetes in the general population, although the exact biological mechanisms involved are still unknown ${ }^{50}$. Given the positive association previously found between alcohol consumption and physical activity, the former may be a proxy of healthy behavior ${ }^{51}$, while abstinent persons may include individuals who stop drinking because of previous health problems. 
Agardh et al. in their meta-analysis found an overall higher risk of diabetes in groups with a low socioeconomic status, specifically in terms of educational level, occupation and income ${ }^{17}$. This is in line with the associations we found between poverty and the risk of diabetes. There is now mounting evidence that socioeconomic factors such as income or education are risk factors for a wide range of health outcomes $^{16}$. For instance, it has been shown that poor people covered by complementary universal health cover are frequently denied care in France ${ }^{52}$. With regards to immigrants, in France in 2015, approximately $31 \%$ were from the European Union, while $45 \%$ were from Africa ${ }^{53}$. We therefore expect that a majority of patients identified as migrants in our study were African. The most recent data indicate that immigrant households have a higher prevalence of poverty, are overrepresented in the less wealthy half of France population, and that almost a third of immigrant households where the head of the household was born in Africa have a standard of living lower than the first decile ${ }^{54}$. The association we found between being born outside France and the risk of diabetes is therefore certainly related to socioeconomic factors, but genetic contributions may make the burden heavier for some sub-populations than for others ${ }^{55}$. We did not find a significant association between elevated coffee consumption and the risk of diabetes after multivariable adjustment, despite robust evidence found in the general population ${ }^{23}$. Given that elevated coffee consumption seems to protect HIV-HCV co-infected patients from liver fibrosis ${ }^{22}$ and that cirrhosis is a cause of diabetes, we may hypothesize that adjusting for fibrosis, as we did, lessens the protective effect of coffee on diabetes.

The main strength of the present study is the sample size and the sampling procedure likely to provide data representative of HCV-infected French patients. Despite its cross-sectional nature, with more than 9,000 patients and a significant 
proportion of cannabis users, it provides the first evidence of the potential protective effect of cannabis use on diabetes among HCV-infected patients. As diabetes diagnosis is more likely to encourage more health-conscious behavior, it is unlikely that reverse causality is involved in the association we found between cannabis use and diabetes. Longitudinal studies are nonetheless required to confirm these findings. Multivariable adjustment for clinical, behavioral and socio-economic variables is another strength of the study. It is now well-recognized that these variables impact to a great extent health outcomes. This study has limitations. Collection of cannabis data during face-to-face interviews with physicians may have led to underreporting of use. However, such underreporting would be unlikely to be different between the two groups (i.e., with and without diabetes). Furthermore, such a bias is less likely for former cannabis users. To further assess the dose-dependent nature of the relationship, more precise data regarding cannabis use would have been valuable. We did not have data regarding diet quality or physical activity, which are known risk factor for diabetes development. However, they are related to BMI which was included, and if they were available, reverse causality would have impaired the interpretation (diabetic patients may be more attentive to their lifestyle). Being able to take into account history of $\mathrm{HCV}$ treatment (information which was not available in our study) would have been beneficial given that interferon-based therapeutic regimens may be involved in type 1 diabetes development $^{6}$. The lack of data differentiating type 2 from type 1 diabetes also impairs the interpretation of the results. However, $\mathrm{HCV}$ is recognized as triggering mostly type 2 diabetes and only occasionally type 1 diabetes $^{6}$. Therefore, given the high prevalence of type 2 diabetes among HCV infected patients and that the relationship between type 2 
diabetes and $\mathrm{HCV}$ is unequivocal ${ }^{56}$, we may expect that the vast majority of diabetes cases were type 2 .

\section{Conclusions}

In conclusion, we found that cannabis use is associated with a lower risk of diabetes in HCV-infected patients. Further studies are needed to longitudinally confirm these results and investigations into cannabis compounds and their biological effects hold great promise for the treatment and prevention of diabetes. 


\section{References}

1. Kaiser $A B$, Zhang N, Pluijm WVD. Global Prevalence of Type 2 Diabetes over the Next Ten Years (2018-2028). Diabetes. 2018;67(Supplement 1):202-LB. doi:10.2337/db18-202-LB

2. Bommer C, Sagalova V, Heesemann E, et al. Global Economic Burden of Diabetes in Adults: Projections From 2015 to 2030. Diabetes Care. 2018;41(5):963-970. doi:10.2337/dc17-1962

3. Engelmann J, Manuwald U, Rubach C, et al. Determinants of mortality in patients with type 2 diabetes: a review. Rev Endocr Metab Disord. 2016;17(1):129-137. doi:10.1007/s11154-0169349-0

4. Blach S, Zeuzem S, Manns M, et al. Global prevalence and genotype distribution of hepatitis C virus infection in 2015: a modelling study. The Lancet Gastroenterology \& Hepatology. 2017;2(3):161-176. doi:10.1016/S2468-1253(16)30181-9

5. Stanaway JD, Flaxman AD, Naghavi M, et al. The global burden of viral hepatitis from 1990 to 2013: findings from the Global Burden of Disease Study 2013. Lancet. 2016;388(10049):10811088. doi:10.1016/S0140-6736(16)30579-7

6. Hammerstad SS, Grock SF, Lee HJ, Hasham A, Sundaram N, Tomer Y. Diabetes and Hepatitis C: A Two-Way Association. Front Endocrinol (Lausanne). 2015;6. doi:10.3389/fendo.2015.00134

7. García-Compeán D, González-González JA, Lavalle-González FJ, González-Moreno El, VillarrealPérez JZ, Maldonado-Garza HJ. Current Concepts in Diabetes Mellitus and Chronic Liver Disease: Clinical Outcomes, Hepatitis C Virus Association, and Therapy. Dig Dis Sci. 2016;61(2):371-380. doi:10.1007/s10620-015-3907-2

8. Younossi Z, Park H, Henry L, Adeyemi A, Stepanova M. Extrahepatic Manifestations of Hepatitis C: A Meta-analysis of Prevalence, Quality of Life, and Economic Burden. Gastroenterology. 2016;150(7):1599-1608. doi:10.1053/j.gastro.2016.02.039

9. Drazilova S, Gazda J, Janicko M, Jarcuska P. Chronic Hepatitis C Association with Diabetes Mellitus and Cardiovascular Risk in the Era of DAA Therapy. Can J Gastroenterol Hepatol. 2018;2018:6150861. doi:10.1155/2018/6150861

10. Serfaty L. Metabolic Manifestations of Hepatitis C Virus: Diabetes Mellitus, Dyslipidemia. Clin Liver Dis. 2017;21(3):475-486. doi:10.1016/j.cld.2017.03.004

11. Edmunds BL, Miller ER, Tsourtos G. The distribution and socioeconomic burden of Hepatitis C virus in South Australia: a cross-sectional study 2010-2016. BMC Public Health. 2019;19. doi:10.1186/s12889-019-6847-5

12. European Monitoring Centre for Drugs and Drug Addiction. Hepatitis C among Drug Users in Europe: Epidemiology, Treatment and Prevention.; 2016. http://www.emcdda.europa.eu/publications/insights/hepatitis-c-among-drug-users-ineurope_en. Accessed August 29, 2018. 
13. Dillon JF, Lazarus JV, Razavi HA. Urgent action to fight hepatitis $\mathrm{C}$ in people who inject drugs in Europe. Hepatology, Medicine and Policy. 2016;1(1):2. doi:10.1186/s41124-016-0011-y

14. Neale J, Tompkins C, Sheard L. Barriers to accessing generic health and social care services: a qualitative study of injecting drug users. Health Soc Care Community. 2008;16(2):147-154. doi:10.1111/j.1365-2524.2007.00739.x

15. Omland $L H$, Osler $M$, Jepsen $P$, et al. Socioeconomic status in HCV infected patients - risk and prognosis. Clin Epidemiol. 2013;5:163-172. doi:10.2147/CLEP.S43926

16. Braveman P, Gottlieb L. The Social Determinants of Health: It's Time to Consider the Causes of the Causes. Public Health Rep. 2014;129(Suppl 2):19-31.

17. Agardh E, Allebeck P, Hallqvist J, Moradi T, Sidorchuk A. Type 2 diabetes incidence and socioeconomic position: a systematic review and meta-analysis. Int J Epidemiol. 2011;40(3):804-818. doi:10.1093/ije/dyr029

18. Sidney S. Marijuana Use and Type 2 Diabetes Mellitus: a Review. Curr Diab Rep. 2016;16(11):117. doi:10.1007/s11892-016-0795-6

19. Carrieri MP, Serfaty L, Vilotitch A, et al. Cannabis Use and Reduced Risk of Insulin Resistance in HIV-HCV Infected Patients: A Longitudinal Analysis (ANRS CO13 HEPAVIH). Clin Infect Dis. 2015;61(1):40-48. doi:10.1093/cid/civ217

20. Adejumo AC, Adegbala OM, Adejumo KL, Bukong TN. Reduced Incidence and Better Liver Disease Outcomes among Chronic HCV Infected Patients Who Consume Cannabis. Can J Gastroenterol Hepatol. 2018;2018:9430953. doi:10.1155/2018/9430953

21. Pol S, Bourliere M, Lucier S, et al. Safety and efficacy of daclatasvir-sofosbuvir in HCV genotype 1-mono-infected patients. J Hepatol. 2017;66(1):39-47. doi:10.1016/j.jhep.2016.08.021

22. Carrieri MP, Protopopescu C, Marcellin F, et al. The impact of coffee consumption on fibrosis and steatosis in HIV-HCV co-infected patients. J Hepatol. November 2017. doi:10.1016/j.jhep.2017.10.025

23. Ding M, Bhupathiraju SN, Chen M, van Dam RM, Hu FB. Caffeinated and decaffeinated coffee consumption and risk of type 2 diabetes: a systematic review and a dose-response metaanalysis. Diabetes Care. 2014;37(2):569-586. doi:10.2337/dc13-1203

24. Sterling Richard K., Lissen Eduardo, Clumeck Nathan, et al. Development of a simple noninvasive index to predict significant fibrosis in patients with HIV/HCV coinfection. Hepatology. 2006;43(6):1317-1325. doi:10.1002/hep.21178

25. World Health Organization. Body mass index - BMI. http://www.euro.who.int/en/healthtopics/disease-prevention/nutrition/a-healthy-lifestyle/body-mass-index-bmi. Published July 9 , 2019. Accessed July 9, 2019.

26. Haute Autorité de Santé (French National Authority for Health). Screening tool for early detection and brief intervention (Outil d'aide au repérage précoce et à l'intervention brève).; 2014. https://www.has-sante.fr/jcms/c_1795221/fr/outil-d-aide-au-reperage-precoce-etintervention-breve-alcool-cannabis-tabac-chez-l-adulte. Accessed October 24, 2019. 
27. Hosmer D W, Lemeshow S. Applied Logistic Regression. Second edition. John Wiley \& Sons, Inc. https://onlinelibrary.wiley.com/doi/book/10.1002/0471722146. Accessed October 8, 2019.

28. Alshaarawy O, Anthony JC. Cannabis Smoking and Diabetes Mellitus: Results from Metaanalysis with Eight Independent Replication Samples. Epidemiology. 2015;26(4):597-600. doi:10.1097/EDE.0000000000000314

29. Rajavashisth TB, Shaheen M, Norris KC, et al. Decreased prevalence of diabetes in marijuana users: cross-sectional data from the National Health and Nutrition Examination Survey (NHANES) III. BMJ Open. 2012;2(1):e000494. doi:10.1136/bmjopen-2011-000494

30. Danielsson AK, Lundin A, Yaregal A, Östenson CG, Allebeck P, Agardh EE. Cannabis Use as Risk or Protection for Type 2 Diabetes: A Longitudinal Study of 18000 Swedish Men and Women. J Diabetes Res. 2016;2016. doi:10.1155/2016/6278709

31. Bancks MP, Pletcher MJ, Kertesz SG, Sidney S, Rana JS, Schreiner PJ. Marijuana use and risk of prediabetes and diabetes by middle adulthood: the Coronary Artery Risk Development in Young Adults (CARDIA) study. Diabetologia. 2015;58(12):2736-2744. doi:10.1007/s00125-015-3740-3

32. Ngueta G, Bélanger RE, Laouan-Sidi EA, Lucas M. Cannabis use in relation to obesity and insulin resistance in the Inuit population. Obesity (Silver Spring). 2015;23(2):290-295.

doi:10.1002/oby.20973

33. Di Marzo V, Piscitelli F, Mechoulam R. Cannabinoids and endocannabinoids in metabolic disorders with focus on diabetes. Handb Exp Pharmacol. 2011;(203):75-104. doi:10.1007/9783-642-17214-4_4

34. Ignatowska-Jankowska B, Jankowski MM, Swiergiel AH. Cannabidiol decreases body weight gain in rats: involvement of CB2 receptors. Neurosci Lett. 2011;490(1):82-84.

doi:10.1016/j.neulet.2010.12.031

35. Farrimond JA, Whalley BJ, Williams CM. Cannabinol and cannabidiol exert opposing effects on rat feeding patterns. Psychopharmacology. 2012;223(1):117-129. doi:10.1007/s00213-012$2697-x$

36. Zampino R, Marrone A, Restivo L, et al. Chronic HCV infection and inflammation: Clinical impact on hepatic and extra-hepatic manifestations. World J Hepatol. 2013;5(10):528-540.

doi:10.4254/wjh.v5.i10.528

37. Lontchi-Yimagou E, Sobngwi E, Matsha TE, Kengne AP. Diabetes mellitus and inflammation. Curr Diab Rep. 2013;13(3):435-444. doi:10.1007/s11892-013-0375-y

38. Pedersen BK. Anti-inflammatory effects of exercise: role in diabetes and cardiovascular disease. Eur J Clin Invest. 2017;47(8):600-611. doi:10.1111/eci.12781

39. Booz GW. Cannabidiol as an Emergent Therapeutic Strategy for Lessening the Impact of Inflammation on Oxidative Stress. Free Radic Biol Med. 2011;51(5):1054-1061. doi:10.1016/j.freeradbiomed.2011.01.007

40. Farooqui MT, Khan MA, Cholankeril G, et al. Marijuana is not associated with progression of hepatic fibrosis in liver disease: a systematic review and meta-analysis. Eur J Gastroenterol Hepatol. 2019;31(2):149-156. doi:10.1097/MEG.0000000000001263 
41. Hu J-H, Chang M-L, Liu N-J, Yeh C-T, Huang T-J. Effect of HCV treatment response on insulin resistance: A systematic review and meta-analysis. Exp Ther Med. 2019;18(5):3568-3578. doi:10.3892/etm.2019.7995

42. Adinolfi LE, Rinaldi L, Marrone A, Giordano M. The effect of sustained virological response by direct-acting antivirals on insulin resistance and diabetes mellitus in patients with chronic hepatitis C. Expert Review of Anti-infective Therapy. 2018;16(8):595-597. doi:10.1080/14787210.2018.1505500

43. Ribaldone DG, Sacco M, Saracco GM. The Effect of Viral Clearance Achieved by Direct-Acting Antiviral Agents on Hepatitis C Virus Positive Patients with Type 2 Diabetes Mellitus: A Word of Caution after the Initial Enthusiasm. J Clin Med. 2020;9(2). doi:10.3390/jcm9020563

44. Tam J, Liu J, Mukhopadhyay B, Cinar R, Godlewski G, Kunos G. Endocannabinoids in liver disease. Hepatology. 2011;53(1):346-355. doi:10.1002/hep.24077

45. Gruden G, Barutta F, Kunos G, Pacher P. Role of the endocannabinoid system in diabetes and diabetic complications. Br J Pharmacol. 2016;173(7):1116-1127. doi:10.1111/bph.13226

46. Jadoon KA, Ratcliffe SH, Barrett DA, et al. Efficacy and Safety of Cannabidiol and Tetrahydrocannabivarin on Glycemic and Lipid Parameters in Patients With Type 2 Diabetes: A Randomized, Double-Blind, Placebo-Controlled, Parallel Group Pilot Study. Diabetes Care. 2016;39(10):1777-1786. doi:10.2337/dc16-0650

47. Kautzky-Willer A, Harreiter J, Pacini G. Sex and Gender Differences in Risk, Pathophysiology and Complications of Type 2 Diabetes Mellitus. Endocr Rev. 2016;37(3):278-316. doi:10.1210/er.2015-1137

48. Pan A, Wang Y, Talaei M, Hu FB, Wu T. Relation of active, passive, and quitting smoking with incident type 2 diabetes: a systematic review and meta-analysis. Lancet Diabetes Endocrinol. 2015;3(12):958-967. doi:10.1016/S2213-8587(15)00316-2

49. Maddatu J, Anderson-Baucum E, Evans-Molina C. Smoking and the Risk of Type 2 Diabetes. Transl Res. 2017;184:101-107. doi:10.1016/j.trsl.2017.02.004

50. Baliunas DO, Taylor BJ, Irving $\mathrm{H}$, et al. Alcohol as a risk factor for type 2 diabetes: A systematic review and meta-analysis. Diabetes Care. 2009;32(11):2123-2132. doi:10.2337/dc09-0227

51. Piazza-Gardner AK, Barry AE. Examining physical activity levels and alcohol consumption: are people who drink more active? Am J Health Promot. 2012;26(3):e95-104. doi:10.4278/ajhp.100929-LIT-328

52. Le défenseur des droits. Les Refus de Soins Opposés Aux Bénéficiaires de La CMU-C, de I'ACS et de l'AME. Paris; 2014. https://www.cmu.fr/fichierutilisateur/fichiers/Rapport_refus_soins_DDD.pdf.

53. Institut National de la Statistique et des Etudes Economiques. Chap. 3.7 - Étrangers - Immigrés. Tableaux de l'économie française. 2019. https://www.insee.fr/fr/statistiques/fichier/3696937/TEF2019.pdf.

54. Institut National de la Statistique et des Etudes Economiques. Chap. 1.22 Niveau de vie et pauvreté des immigrés. Les revenus et le patrimoine des ménages. 2018. https://www.google.com/url?sa=t\&rct=j\&q=\&esrc=s\&source=web\&cd=2\&cad=rja\&uact=8\&ved 
=2ahUKEwjc36GW4uHjAhXM34UKHYm0CaIQFjABegQIBBAC\&url=https\%3A\%2F\%2Fwww.insee. fr\%2Ffr\%2Fstatistiques\%2Ffichier\%2F3549496\%2FREVPMEN18_F1.22_niv-pauvimmi.pdf\&usg=AOvVaw1Dc_kU8Ui-TwgZ_ljrCsFK.

55. Cheng $C-Y$, Reich $D$, Haiman $C A$, et al. African ancestry and its correlation to type 2 diabetes in African Americans: a genetic admixture analysis in three U.S. population cohorts. PLOS ONE. 2012;7(3):e32840. doi:10.1371/journal.pone.0032840

56. Antonelli A, Ferrari SM, Giuggioli D, et al. Hepatitis $C$ virus infection and type 1 and type 2 diabetes mellitus. World J Diabetes. 2014;5(5):586-600. doi:10.4239/wjd.v5.i5.586 


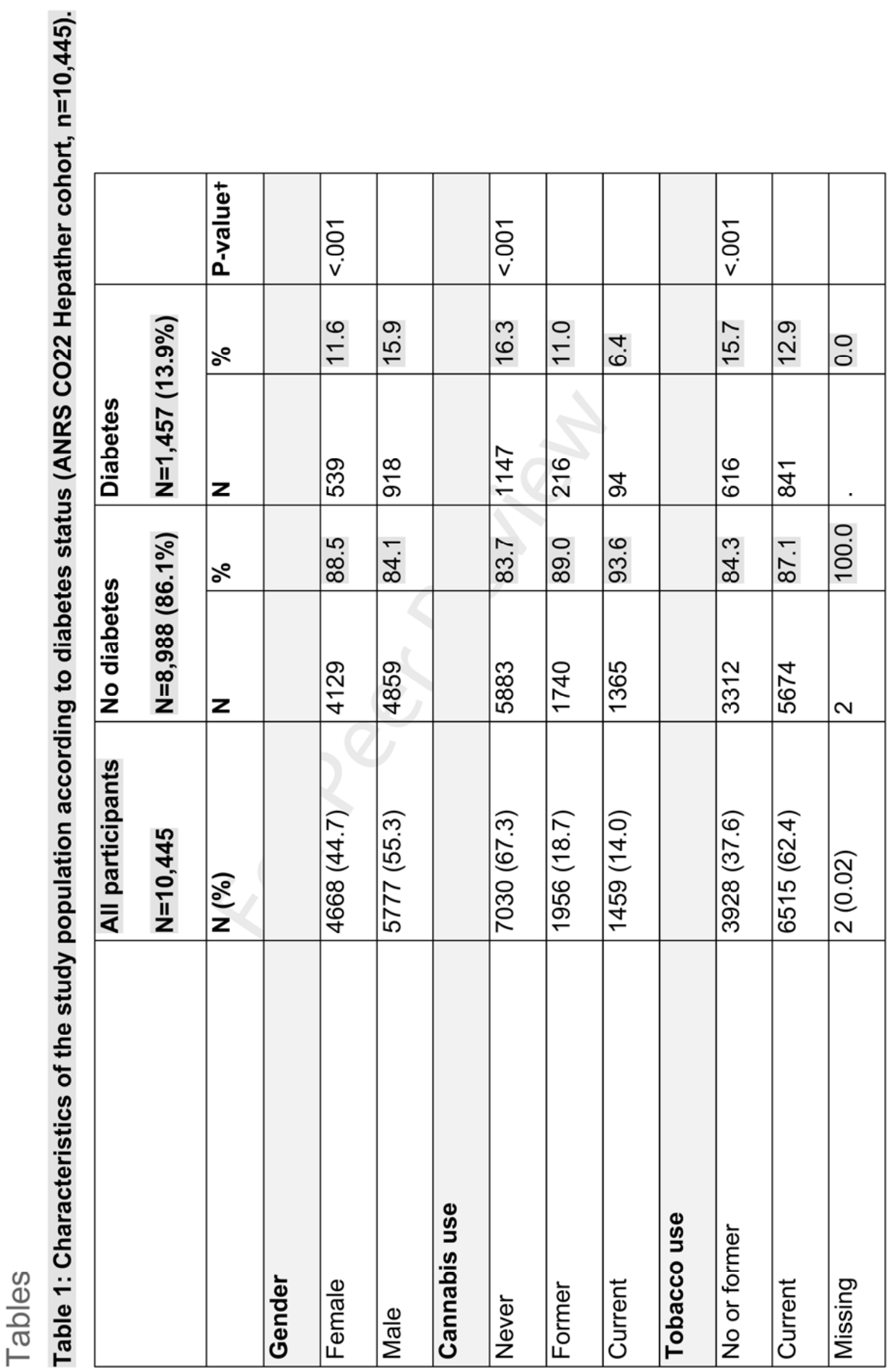




\begin{tabular}{|c|c|c|c|c|c|c|c|c|c|c|c|c|c|c|c|}
\hline & 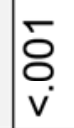 & & & 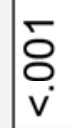 & & & & & & 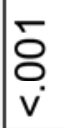 & & & & & $\underset{\mathrm{o}}{\mathrm{O}}$ \\
\hline & 호 & $\stackrel{m}{=}$ & & $\check{\theta}$ & $\bar{\sigma}$ & $\begin{array}{l}\infty \\
\oplus \\
\varrho\end{array}$ & 옹 & $\begin{array}{l}0 \\
0 \\
0\end{array}$ & & 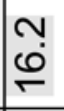 & 움 & $\stackrel{m}{\sigma}$ & 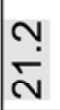 & & $\stackrel{\leftrightarrow}{\stackrel{\circ}{\sim}}$ \\
\hline & $\begin{array}{l}\infty \\
\infty \\
\stackrel{0}{0}\end{array}$ & :్ల & & $\bar{N}$ & 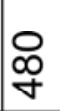 & 令 & 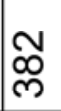 & $\stackrel{10}{-}$ & & 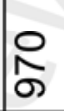 & 饥 & $\bar{q}$ & $\mp$ & & $\begin{array}{l}\mathscr{Q} \\
\mathscr{\infty}\end{array}$ \\
\hline & $\begin{array}{l}\infty \\
\dot{0} \\
\infty\end{array}$ & 夙 & & $\begin{array}{l}\mathscr{~} \\
\ddot{\Omega}\end{array}$ & ه্. & $\underset{\infty}{\infty}$ & ㅁ. & 吕 & & $\begin{array}{l}\infty \\
\infty \\
\infty\end{array}$ & - & 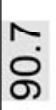 & $\begin{array}{l}0 \\
\infty \\
\infty \\
\infty\end{array}$ & & \\
\hline & बे & ळ్ & & స్లి & $\underset{f}{\stackrel{g}{f}}$ & 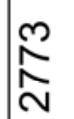 & ֶָ) & হ & & 芯 & 尔 & ষ্ণ & $\bar{q}$ & & 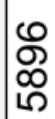 \\
\hline & $\begin{array}{l}\infty \\
\infty \\
\infty \\
0 \\
\infty \\
\infty \\
\tilde{N} \\
\tilde{\infty}\end{array}$ & 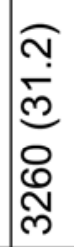 & & 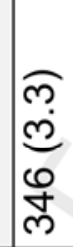 & 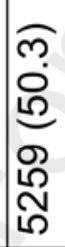 & 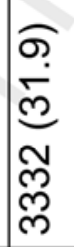 & 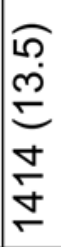 & $\begin{array}{l}\tilde{\sigma} \\
\dot{e} \\
\text { ó }\end{array}$ & & 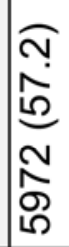 & 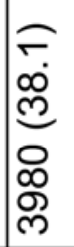 & 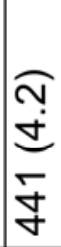 & 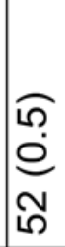 & & 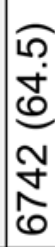 \\
\hline 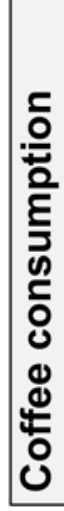 & 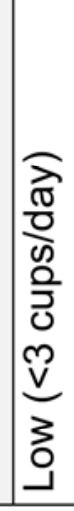 & 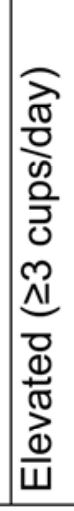 & 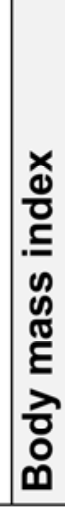 & 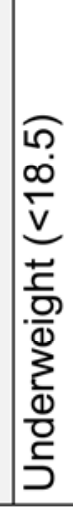 & 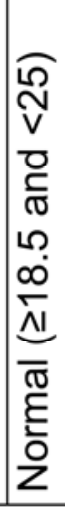 & 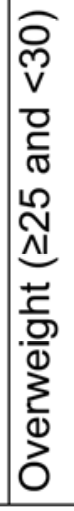 & 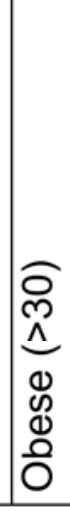 & 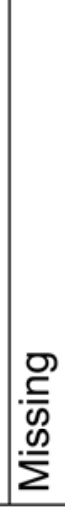 & 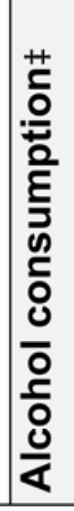 & 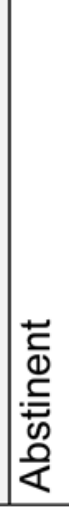 & $\begin{array}{l}\frac{0}{0} \\
\frac{\pi}{0} \\
\frac{0}{0} \\
\frac{0}{2} \\
\end{array}$ & 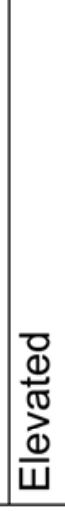 & 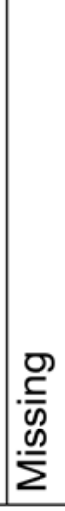 & 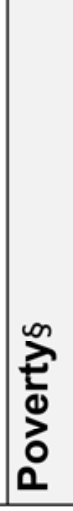 & z \\
\hline
\end{tabular}



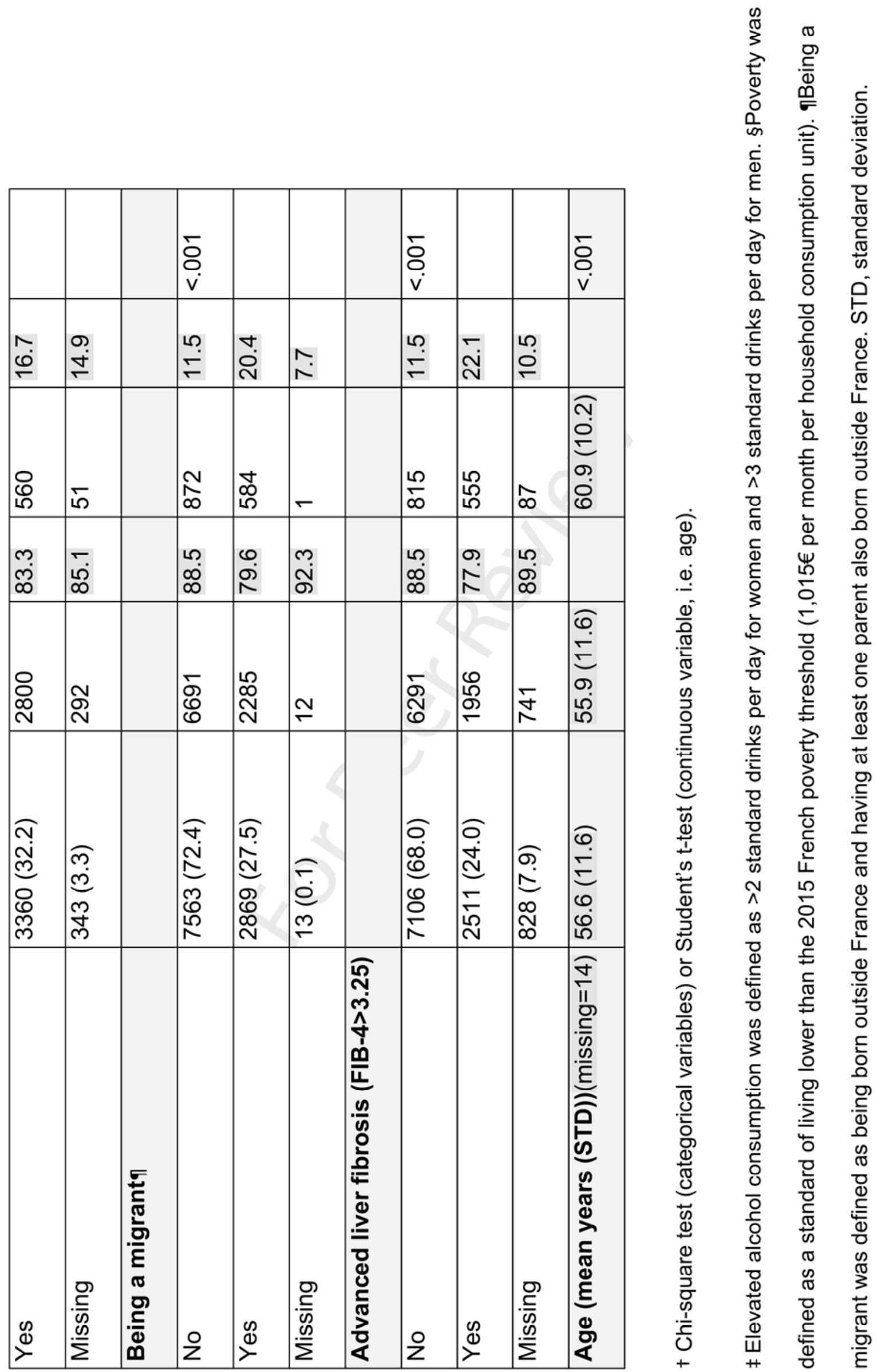

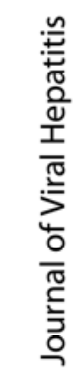




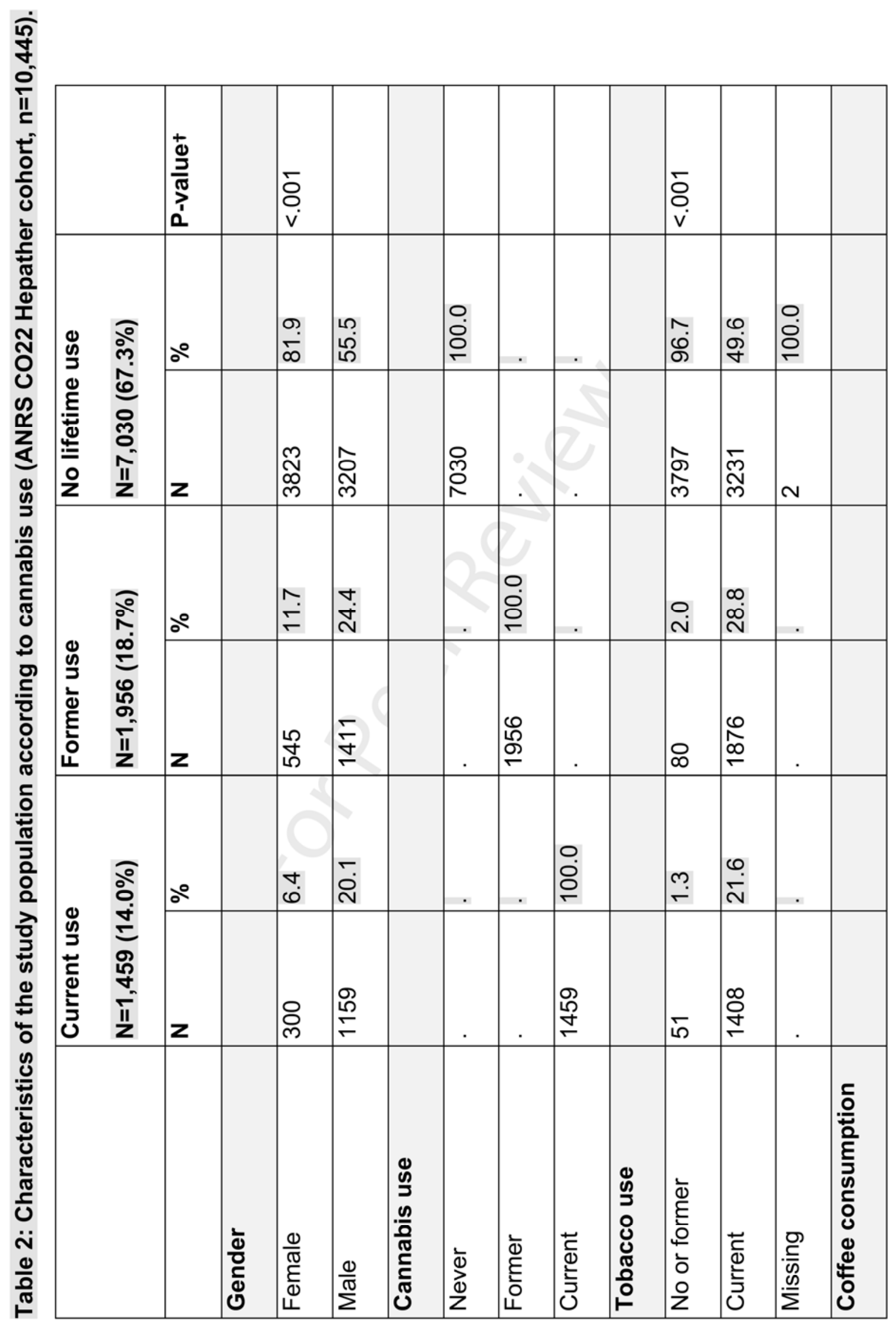




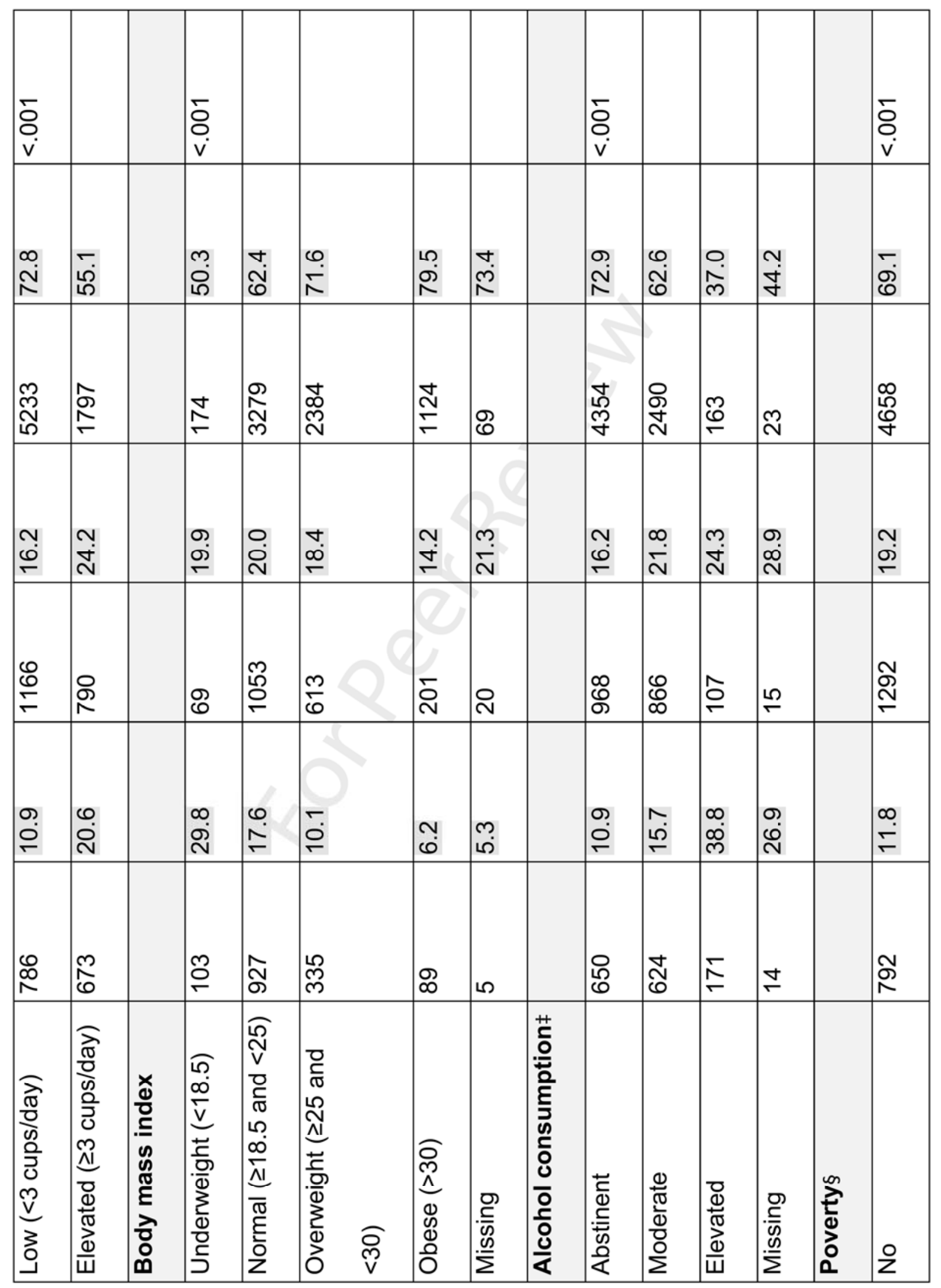




\begin{tabular}{|c|c|c|c|c|c|c|c|c|c|c|c|c|}
\hline & & & $\begin{array}{l}\overline{8} \\
\text { v } \\
\text {. }\end{array}$ & & & & & $\begin{array}{l}\check{\bigcirc} \\
\text { v }\end{array}$ & & & $\begin{array}{l}\check{8} \\
\text { v } \\
\text { v }\end{array}$ & \\
\hline ๙்ָ & م & & ?ִ & $\begin{array}{l}\infty \\
\underset{\infty}{\infty}\end{array}$ & $\begin{array}{l}\text { ڤ. } \\
\text { م) }\end{array}$ & & & $\begin{array}{l}0 \\
0 \\
0\end{array}$ & $\stackrel{N}{\circ}$ & $\begin{array}{l}\circ \\
0 \\
0 \\
0\end{array}$ & & \\
\hline$\frac{O}{N}$ & $\hat{\omega}$ & & 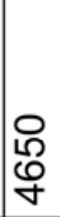 & 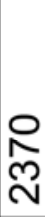 & 으 & & & ণิ & 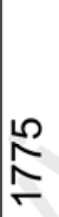 & గొ & 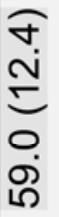 & \\
\hline $\begin{array}{l}n \\
\infty \\
\infty\end{array}$ & $\stackrel{n}{\stackrel{0}{\sim}}$ & & $\frac{\text { ạ }}{\grave{N}}$ & ?ִ. & $\stackrel{+}{\stackrel{7}{\circ}}$ & & & $\begin{array}{l}\text { 움 } \\
\text { م }\end{array}$ & $\stackrel{0}{\stackrel{0}{c}}$ & $\begin{array}{l}\infty \\
\stackrel{\infty}{\rightleftharpoons}\end{array}$ & & \\
\hline ָָ & 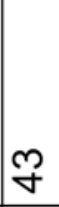 & & 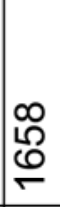 & ঙ্ণী & $N$ & & & $\stackrel{\text { లె }}{\ulcorner}$ & g & $\stackrel{\oplus}{6}$ & 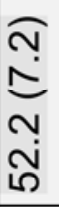 & \\
\hline $\begin{array}{l}\infty \\
\infty \\
\infty\end{array}$ & $\begin{array}{l}\mathscr{0} \\
\sigma^{\prime}\end{array}$ & & $\begin{array}{l}\mathscr{0} \\
\varrho\end{array}$ & $\tau$ & N & & & $\begin{array}{l}0 \\
\stackrel{10}{\circ}\end{array}$ & $\stackrel{\infty}{\check{r}}$ & $\stackrel{\sim}{\stackrel{N}{\sim}}$ & & \\
\hline ల్ & m & & 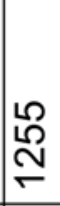 & గ్ల & - & & & ஜ్రి & ำ & 음 & 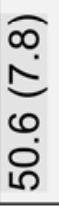 & \\
\hline$\stackrel{\mathscr{D}}{\mathcal{1}}$ & 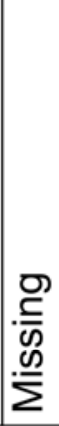 & 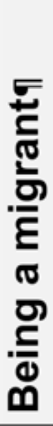 & 을 & $\stackrel{\infty}{\downarrow}$ & 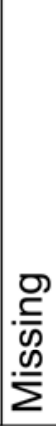 & 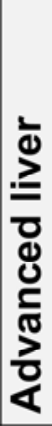 & 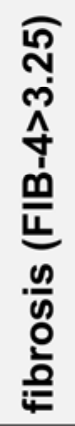 & ㅇ & $\stackrel{\infty}{\infty}$ & 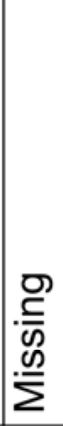 & 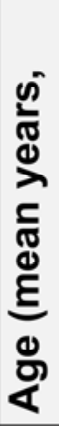 & 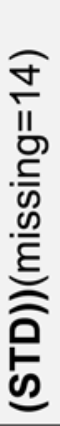 \\
\hline
\end{tabular}


m

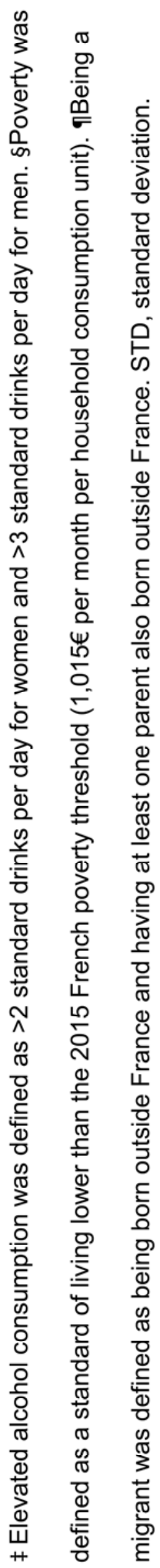


Table 3: Factors associated with the presence of diabetes, logistic regression models, univariable and multivariable analyses (ANRS CO22 Hepather cohort, $n=10,445)$

Univariable analyses Multivariable analysis

$$
(n=10,445) \quad(n=9,215)
$$

OR $\quad 95 \% \mathrm{Cl} \quad$ P-value $\quad$ AOR $95 \% \mathrm{Cl}$ P-value

$\begin{array}{llllllll}\text { Gender } & \\ \text { Female } & 1 & & & & & \\ & & & & & & & \\ & & & & & & & \\ \text { Male } & 1.45 & 1.29-1.62 & <.001 & 1.86 & 1.61- & <.001\end{array}$

\section{Cannabis use}

No lifetime use

1

1

$\begin{array}{llllllll}\text { Former } & 0.64 & 0.55-0.74 & <.001 & 0.81 & 0.67- & 0.031 \\ & & & & & 0.98 & \\ \text { Current } & 0.35 & 0.28-0.44 & <.001 & 0.49 & 0.38- & <.001\end{array}$

Tobacco use

No lifetime use or former use 1 


$\begin{array}{lcccccc}\text { Current } & 0.80 & 0.71-0.89 & <.001 & 1.17 & 1.01- & 0.036 \\ \text { Coffee consumption } & & & & & & \\ & & & & & & \\ \text { Low (<3 cups/day) } & 1 & & & & \\ \text { Elevated ( } \geq 3 \text { cups/day) } & 0.72 & 0.63-0.81 & <.001\end{array}$

\section{Body mass index}

$\begin{array}{lllllll}\text { Underweight }(<18.5) & 0.64 & 0.41-1.01 & 0.056 & 0.92 & & 0.57- \\ 0.708\end{array}$

Normal $(\geq 18.5$ and $<25) \quad 1$

$\begin{array}{lrlllllll}\text { Overweight }(\geq 25 \text { and }<30) & 2.01 & 1.76-2.29 & <.001 & 1.65 & 1.43- & <.001 \\ & & & & & & & \\ & & & & & & & \\ & & & & & & & \\ \text { Obese }(>30) & 3.69 & 3.17-4.28 & <.001 & 3.33 & & <.001\end{array}$

\begin{tabular}{|c|c|c|c|c|c|c|}
\hline Alcohol consumption $†$ & & & & & & \\
\hline Abstinent & 1 & & & 1 & & \\
\hline Moderate & 0.63 & $0.56-0.71$ & $<.001$ & 0.77 & $\begin{array}{l}0.68- \\
0.89\end{array}$ & $<.001$ \\
\hline Elevated & 0.53 & $0.38-0.73$ & $<.001$ & 0.72 & $\begin{array}{l}0.50- \\
1.03\end{array}$ & 0.075 \\
\hline
\end{tabular}



No
1
1
Yes
$\begin{array}{llll}1.39 & 1.24-1.57 \quad<.001 & 1.32\end{array}$
$1.15-$
$<.001$

\title{
Being a migrant $\S$
}

No

1

1

Yes

$1.96 \quad 1.75-2.20 \quad<.001 \quad 1.51$

$1.31-$

$<.001$

1.74

\begin{abstract}
Advanced liver fibrosis
(FIB-4>3.25)

No

1

1

Yes

$\begin{array}{llll}2.19 & 1.94-2.47 & <.001 & 1.71\end{array}$

$1.50-$

1.95

$<.001$

\section{Age (years)}

$1.04 \quad 1.03-1.05 \quad<.001 \quad 1.04$

1.03-

1.05

$<.001$
\end{abstract}

+ Elevated alcohol consumption was defined as $>2$ standard drinks per day for women and >3 standard drinks per day for men. ¥Poverty was defined as a standard of living lower than the 2015 French poverty threshold $(1,015 €$ per month per household consumption unit). $\S$ Being a migrant was defined as being born outside France and having at least one parent also born outside France. (A)OR, (adjusted) odds ratio; $\mathrm{Cl}$, confidence interval. 
Figure 1: Flowchart of the study population (ANRS CO22 Hepather cohort). 


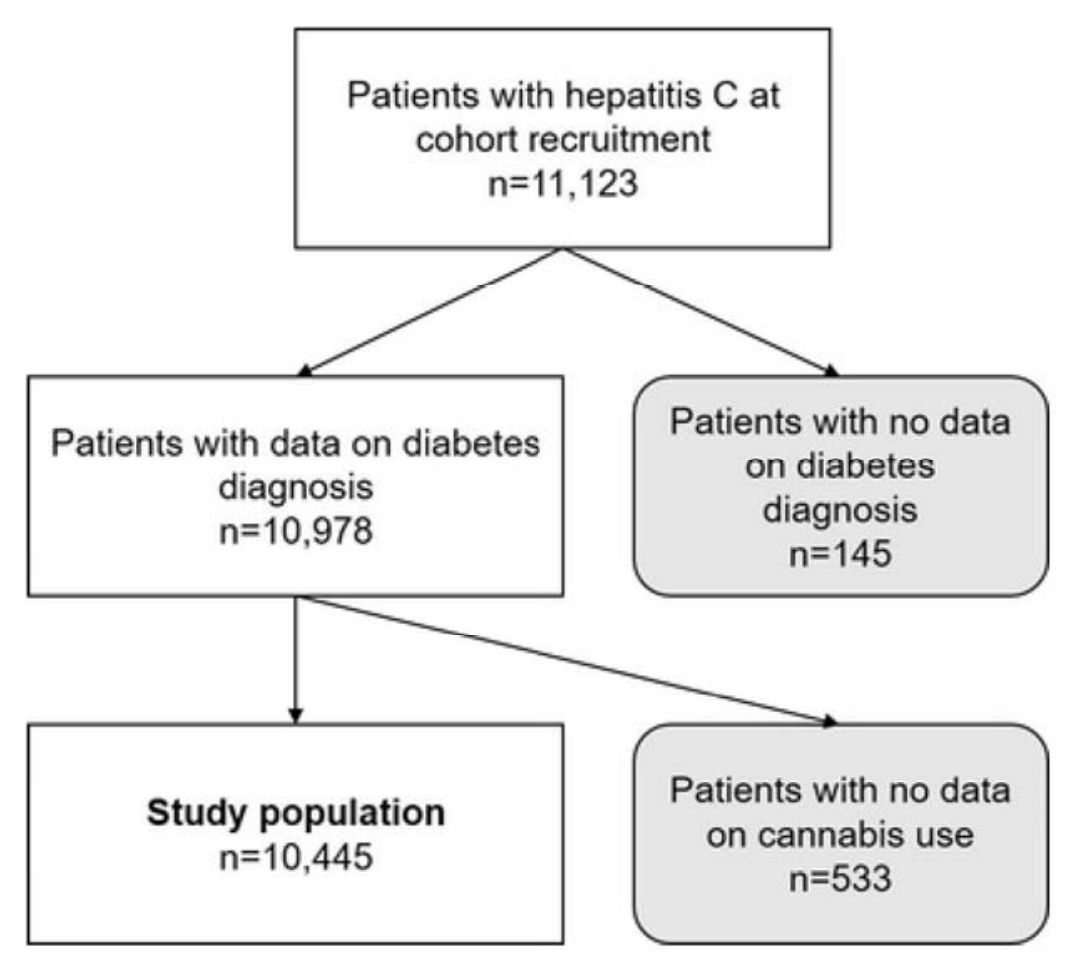

Figure 1: Flowchart of the study population (ANRS CO22 Hepather cohort). $34 \times 30 \mathrm{~mm}(300 \times 300 \mathrm{DPI})$ 
Supporting table 1: Factors associated with the presence of diabetes in patients without advanced fibrosis, logistic regression models, univariable and multivariable analyses (ANRS CO22 Hepather cohort, $n=7,106$ )

Univariable analyses Multivariable analysis

\begin{tabular}{lllll}
\multicolumn{3}{c}{$(\mathrm{n}=7,106)$} & & $(\mathrm{n}=6,813)$ \\
& & & & \\
\hline OR & $\mathbf{9 5 \%} \mathbf{C l}$ & P-value AOR & $\mathbf{9 5 \%} \mathbf{~ C l}$ & P-value
\end{tabular}

\begin{tabular}{|c|c|c|c|c|c|}
\hline Gender & & & & & \\
\hline Female & 1 & & $<.001$ & 1 & $<.001$ \\
\hline Male & 1.38 & $1.19-1.60$ & & 1.83 & $\begin{array}{l}1.53- \\
2.19\end{array}$ \\
\hline
\end{tabular}

Cannabis use
$\begin{array}{lllll} & & & \\ \text { No lifetime use } & 1 & <.001 & 1 & 0.001\end{array}$

$\begin{array}{llll}\text { Former } & 0.66 & 0.54-0.80 & 0.89\end{array}$

$0.70-$

1.14

$0.40-$

$\begin{array}{llll}\text { Current } & 0.34 & 0.26 & 0.55 \\ & & 0.75\end{array}$

Tobacco use

$\begin{array}{lllll}\text { No lifetime use or former use } & 1 & 0.011 & 1 & 0.006\end{array}$

$\begin{array}{lllll}\text { Current } & 0.83 & 0.71-0.96 & 1.30 & \\ & & & & 1.57\end{array}$

Coffee consumption

Low $(<3$ cups/day) $\quad 1 \quad 0.010$ 
Elevated ( $\geq 3$ cups/day) $\quad 0.82 \quad 0.70-0.95$

\section{Body mass index}

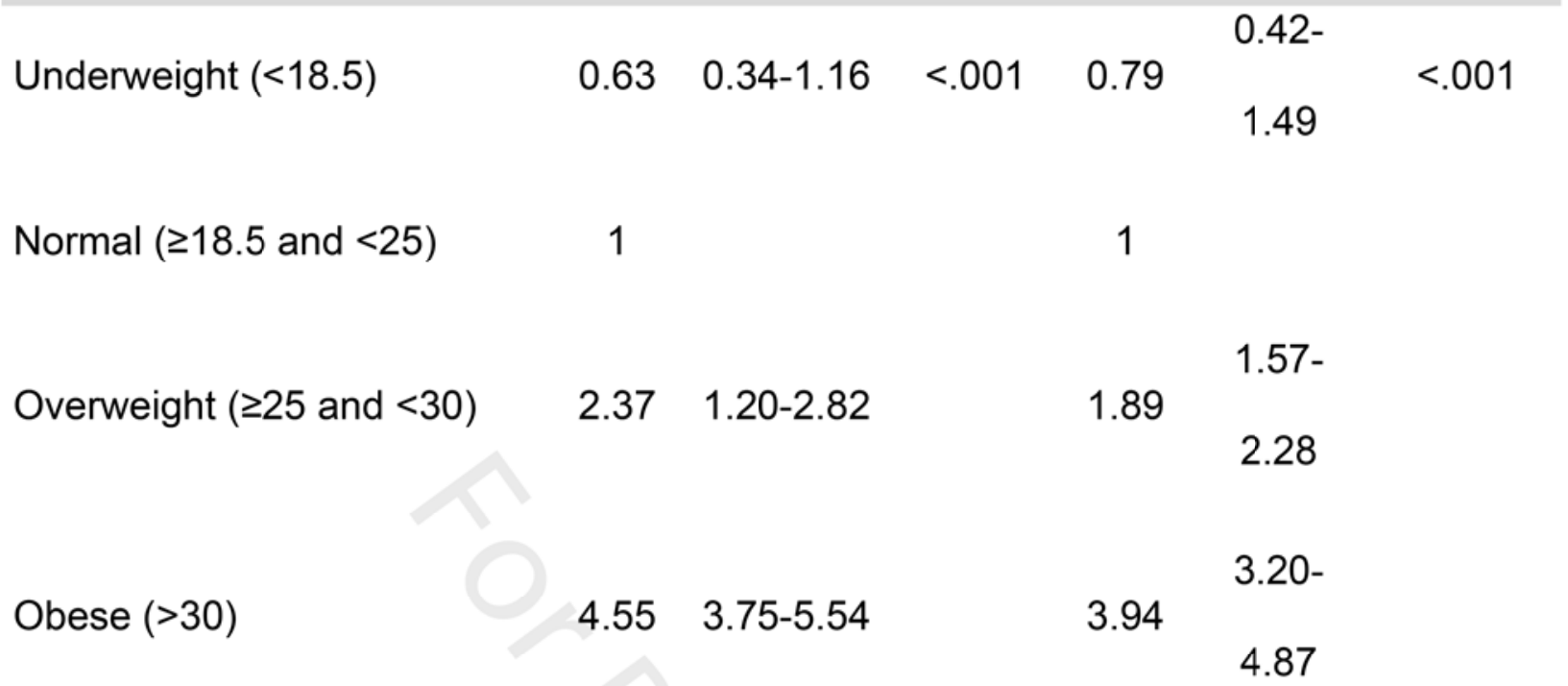

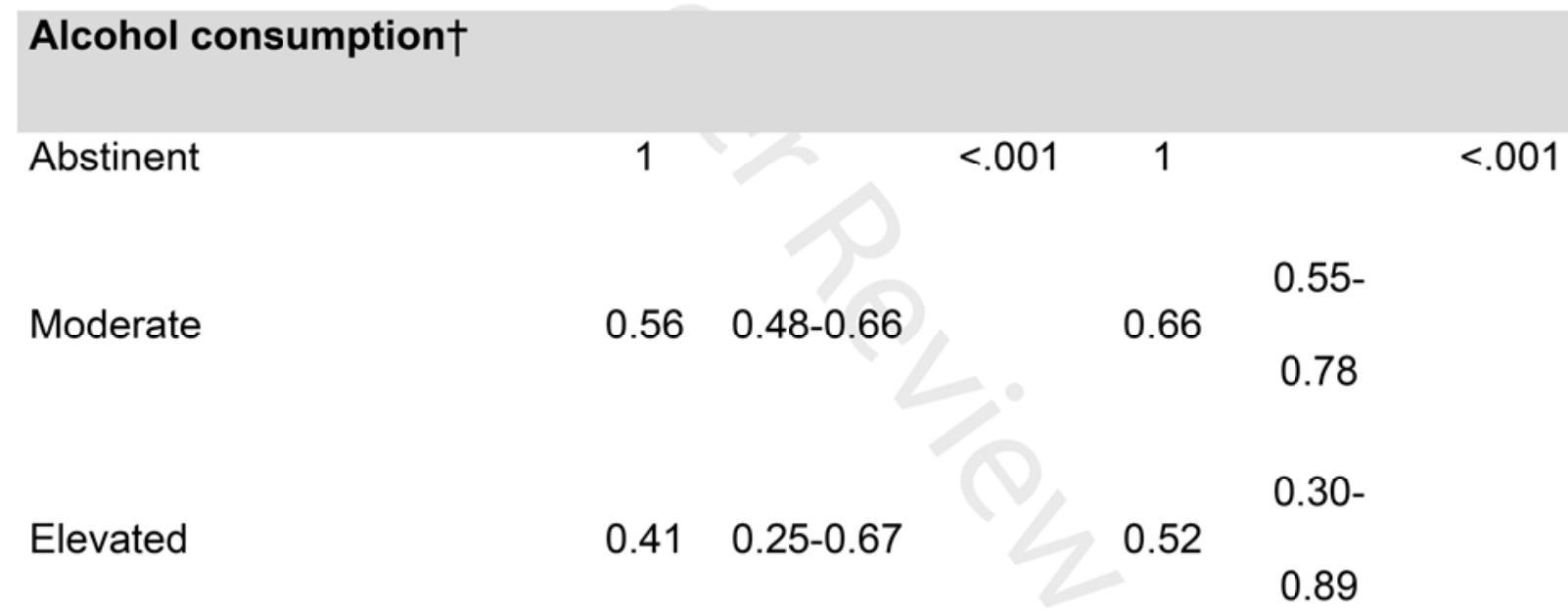

Poverty $\ddagger$

$\begin{array}{lllll}\text { No } & 1 & <.001 & 1 & 0.008\end{array}$

Yes

$1.33 \quad 1.15-1.55$

\section{Being a migrant§}

No

1

$<.001$

$<.001$ 
Yes

\section{$1.05 \quad 1.04-1.05 \quad<.001 \quad 1.05$}

$1.04-$

Age (years)

\subsection{6}

$<.001$

\section{† Elevated alcohol consumption was defined as $>2$ standard drinks per day for women and} >3 standard drinks per day for men. ¥Poverty was defined as a standard of living lower than the 2015 French poverty threshold $(1,015 €$ per month per household consumption unit). $\S$ Being a migrant was defined as being born outside France and having at least one parent also born outside France. (A)OR, (adjusted) odds ratio; $\mathrm{Cl}$, confidence interval. 
Supporting table 2: Factors associated with the presence of diabetes in patients with advanced fibrosis, logistic regression models, univariable and multivariable analyses (ANRS CO22 Hepather cohort, $n=2,511$ )

Univariable analyses Multivariable analysis

$$
(n=2,511) \quad(n=2,410)
$$

OR $\quad 95 \% \mathrm{Cl} \quad$ P-value $\quad$ AOR $95 \% \mathrm{Cl}$ P-value

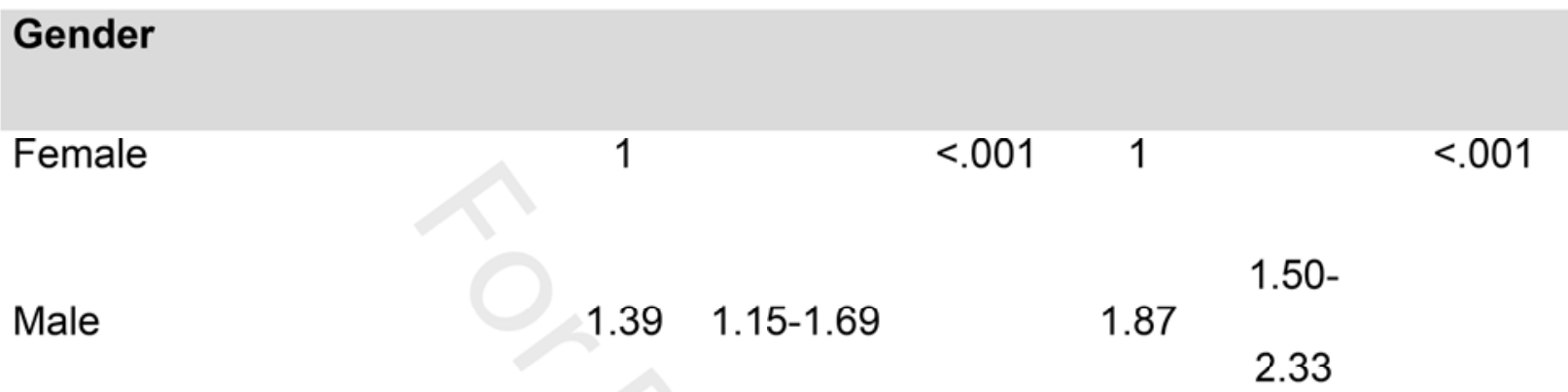

Cannabis use
$\begin{array}{lllll} & \\ \text { No lifetime use } & 1 & <.001 & 1 & <.001\end{array}$
Former
$0.62 \quad 0.47-0.81$
0.66
$\begin{array}{ll}0.89 & 0.69\end{array}$
Current
$0.330 \quad 0.23-0.50$
0.39
$0.25-$
0.60

0.49-

\section{Coffee consumption}

Low (<3 cups/day) $\quad 1 \quad 0.214$ 
Elevated ( $\geq 3$ cups/day) $\quad 0.85 \quad 0.66-1.20$

Body mass index

\begin{tabular}{|c|c|c|c|c|c|c|}
\hline Underweight $(<18.5)$ & 0.88 & $0.45-1.69$ & $<.001$ & 1.14 & $\begin{array}{l}0.56- \\
2.31\end{array}$ & $<.001$ \\
\hline Normal $(\geq 18.5$ and $<25)$ & 1 & & & 1 & & \\
\hline Overweight ( $\geq 25$ and $<30$ ) & 1.50 & $1.21-1.85$ & & 1.31 & $\begin{array}{l}1.04- \\
1.64\end{array}$ & \\
\hline Obese $(>30)$ & 2.57 & $1.99-3.31$ & & 2.43 & $\begin{array}{l}1.85- \\
3.19\end{array}$ & \\
\hline
\end{tabular}

\begin{tabular}{|c|c|c|}
\hline Alcohol c & & \\
\hline Abstinent & 1 & \\
\hline Moderate & 0.89 & $0.73-1.10$ \\
\hline Elevated & 0.64 & $0.41-1.00$ \\
\hline
\end{tabular}

Povertył

$\begin{array}{lllll}\text { No } & 1 & 0.008 & 1 & 0.011\end{array}$

Yes

$1.30 \quad 1.07-1.58$

1.34

$1.07-$

1.67

\section{Being a migrant§}

No

$1<.001$

1

0.001 
Yes

$1.89 \quad 1.55-2.29$

1.45

$1.16-$

1.81

$\begin{array}{llllll}\text { Age (years) } & 1.02 & 1.01-1.03 & <.001 & 1.05 & 1.04 \\ & & & & & 1.06\end{array}$

0.001

† Elevated alcohol consumption was defined as $>2$ standard drinks per day for women and >3 standard drinks per day for men. ‡Poverty was defined as a standard of living lower than the 2015 French poverty threshold $(1,015 €$ per month per household consumption unit). $\S$ Being a migrant was defined as being born outside France and having at least one parent also born outside France. (A)OR, (adjusted) odds ratio; $\mathrm{Cl}$, confidence interval. 